\title{
Produtos educacionais de um curso de mestrado profissional em ensino de ciências
}

Maria Cristina do A. Moreira maria.amaral@ifri.edu.br 0000-0002-8760-6341

Instituto Federal do Rio de Janeiro PROPEC, Nilópolis, RJ, Brasil

Giselle Rôças

giselle.rocas@ifri.edu.b

0000-0002-1669-7725

Instituto Federal do Rio de Janeiro PROPEC, Nilópolis, RJ, Brasil

Marcus Vinicius Pereira marcus.pereira@ifri.edu.br 0000-0002-8203-7805

nstituto Federal do Rio de Janeiro PROPEC, Nilópolis, RJ, Brasil

Maylta Brandão dos Anjos maylta.anjos@ifrj.edu.br 0000-0001-6272-5056

Instituto Federal do Rio de Janeiro

PROPEC, Nilópolis, RJ, Brasil

\section{RESUMO}

Como os produtos educacionais de um curso estão distribuídos dentro das categorias propostas pelo documento de área de Ensino nos últimos seis anos? O que as dissertações de MP indicam serem seus objetivos em relação ao ensino de ciências ao proporem os produtos educacionais? Pautados nas perguntas de pesquisa descritas, o artigo refere-se aos produtos educacionais produzidos em um Mestrado Profissional em Ensino de Ciências, buscando compreender como tais produções contribuem e/ou reforçam abordagens de ensino de ciências. A pesquisa qualitativa apresenta o mapeamento dos produtos educacionais do programa de pós-graduação do Instituto Federal do Rio de Janeiro e a análise dessas propostas em interface com a educação científica veiculada nos produtos Os resultados destacaram preferências- as mídias educacionais e os materiais textuais. A pesquisa mostrou a precariedade de produtos educacionais relacionados com a divulgação científica e a extensão acadêmica. Apontou a necessidade de aprofundar a prática de ensino assim como suas possibilidades na formação de mestres profissionais do ensino de ciências.

PALAVRAS-CHAVE: Mestrado profissional. Produtos educacionais. Ensino de ciências. 


\section{PROBLEMATIZAÇÃO}

A educação científica, em alguma instância, envolve a criação e a utilização de materiais educativos que atuam ou não como recursos pedagógicos por alunos e professores de ciências (POSSOLI; CURY, 2009). As características desses materiais são influenciadas por aspectos relacionados a sua produção, consumo e/ou circulação, além de uma demanda específica para resolução de determinadas situações do cotidiano escolar. Podem ser compreendidos como objetos pedagógicos, com papel político e epistemológico, reestabelecendo aos professores que os produzem de forma crítica e reflexiva o saber legítimo, oriundo do repertório teórico e da prática cotidiana, unindo o saber-ser, o saber formalizado e o saber-fazer esperados na competência de um docente (CRUZ, 2001). De acordo com Rangel (2005, p. 26-27), "qualquer ferramenta utilizada para o ensino e aprendizagem é um material didático", e deve "abrir um caminho para uma comunicação eficiente entre as pessoas envolvidas no processo pedagógico" na interação entre professores e alunos em torno do assunto estudado, buscando alcançar as metas estabelecidas.

Diferentes nomenclaturas são encontradas na literatura como representações possíveis para esses artefatos pedagógicos, tais como materiais educativos (POSSOLI; CURY, 2009), objetos de aprendizagem (BALATSOUKAS et al., 2008), material didático (RANGEL, 2005), produtos educacionais (BRASIL, 2013), além de outras expressões que se voltam a problematizar os recursos didático-pedagógicos utilizados em todos os níveis de ensino para mediar o processo de ensino e aprendizagem. Neste estudo, optamos pela terminologia Produtos Educacionais $(\mathrm{PE})$, primeiramente, por estar em consonância com o documento da área de Ensino (BRASIL, 2013), e, por conseguinte, acompanhando a nomenclatura utilizada pela política pública associada à modalidade de Mestrado Profissional (MP). Outro motivo refere-se ao fato de que compreendemos os PE para além dos materiais educativos e dos objetos de aprendizagem, uma vez que além de estarem expressos em modos representativos de um texto, em forma multimodal e em uma conjunção de modos semióticos (escrito, visual, sonoro, gestual, e outros), são, em sua maioria, criados, elaborados, validados por docentes da escola básica durante a sua formação continuada (KRESS; VAN LEEUWEN, 2006).

Moreira (2004, p. 134) considera que a investigação de um curso de MP na área de ensino, diferentemente da modalidade acadêmica, tem perfil mais "aplicado, descrevendo o desenvolvimento de processos ou produtos de caráter educativo, visando à melhoria da educação na área específica", e que, em alguma instância, o resultado da investigação dos mestrandos pode contribuir para a atividade semelhante de outros profissionais com base em um olhar mais esmiuçado e analítico sobre a ação profissional em diálogo entre teoria e prática. Além disso, o ganho obtido a partir de um MP extrapola a possibilidade de um PE ser validado e disponibilizado para outros professores, mas amplia a oportunidade real na qual um professor se debruça sobre sua prática, avalia um problema real que o motivou a recorrer à academia e busca solução possível e pautada em reflexão teórico-metodológica (LEODORO; BALKINS, 2010; CAVALCANTE, 2015). A importância do $\mathrm{PE}$, desenvolvido por um profissional nesse contexto, reside na possibilidade de gerar ensinamentos aos alunos e na própria práxis do professor, tornando-a mais crítica, reflexiva, fundamentada e contextualizada. 
Apesar disso, o MP tem sido criticado por alguns pesquisadores que consideram essa modalidade de pós-graduação sem muita preocupação com o embasamento teórico. As críticas aos MP não ficam circunscritas à área de Ensino, como podemos ver em Spink (1997) e Fernandes (2005). Essa modalidade visa aplicar o conhecimento gerado na universidade em setores como empresas, comunidades, educação pública, saúde, entre outros, buscando expandir a relação entre instituições de ensino superior e a sociedade (BRASIL, 2009). Nesse sentido, considerando mais de vinte anos de existência dessa modalidade de pósgraduação e mais de vinte e cinco mil formados pelos MP em diferentes áreas do conhecimento (CGEE, 2012; 2015), entende-se como positivo o estabelecimento de qualidade na formação desses profissionais, ao mesmo tempo em que não houve geração de concorrência com os pós-graduados na modalidade de mestrado acadêmico (MA). O crescimento do MP entre 2010 e 2015 foi superior ao do MA considerando que "a média da taxa de crescimento anual do número de títulos de mestrado profissional concedidos foi de $13,1 \%$, enquanto a mesma taxa de títulos de mestrado acadêmico expandiu-se em apenas 4,6\%" (CGEE, 2015, p. 61), e, somente em 2014, titularam-se 5.723 mestres profissionais. Evidenciando essa não concorrência entre MP e MA, destacamos a taxa de emprego formal entre os anos de 2009 e 2014, que se manteve praticamente constante, sendo a dos egressos do MP cerca de 10 pontos percentuais maiores do que a do MA (CGEE, 2015), e a maioria dos egressos mantiveram seus empregos, pois já estavam posicionados no mercado de trabalho antes de entrarem no sistema nacional de pós-graduação.

A modalidade profissional vem sendo compreendida e defendida em outras áreas além do Ensino. Scarano e Oliveira (2005) defendem o MP para a área de biodiversidade e suas correlatas ambientais, uma vez que nem todas as áreas de conhecimento da Coordenação de Aperfeiçoamento de Pessoal de Nível Superior (CAPES) valorizam da mesma forma essa modalidade. A análise demográfica realizada pelo CGEE (2015) entre 2004 e 2014 destaca o crescimento diferenciado dos MP entre as áreas de conhecimento (Figura 1).

Figura 1 - Variação percentual entre 2004 e 2014 da participação do número de títulos de mestrado profissional no número total de títulos de mestrado concedidos no Brasil por grande área do conhecimento.

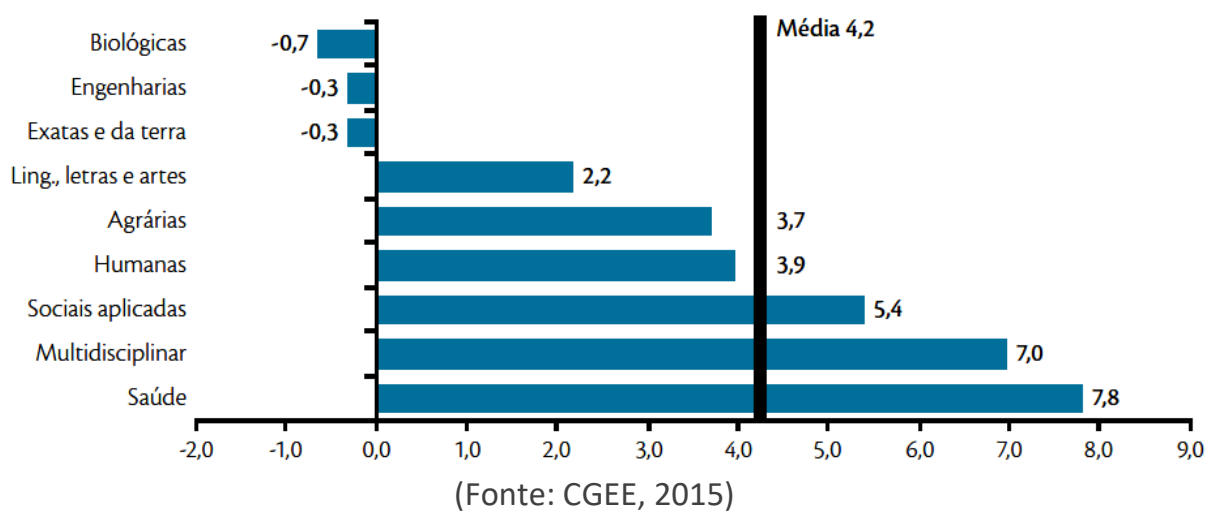

Em estudo demográfico recente (CGEE, 2015, p. 124), identificou-se que os mestres titulados em ambas as modalidades, acadêmica e profissional, têm conseguido espaço no mercado de trabalho e "o ranking é liderado pela área de Ensino, que alcançou 85,7\% de taxa de emprego formal, índice que fica 19,9 pontos percentuais acima da média de todas as áreas". Considerando que a área de Ensino 
possui majoritariamente mestrados profissionais, tal resultado confere qualidade aos mesmos por meio do reconhecimento do mercado de trabalho. Por outro lado, apesar da mais alta taxa de emprego formal, a área de Ensino tem uma das mais baixas taxas de mestres que também se titulam no doutorado (dado que não deve ser analisado isoladamente). Ao consultar os relatórios de dados enviados pelo Coleta na Plataforma Sucupira da CAPES, constata-se que foram formados na área de ensino: 1.035 mestres (511 no MP e 524 no MA) contra 180 doutores no ano de 2013; 1.265 mestres (643 no MP e 622 no MA) contra 201 doutores no ano de 2014; 1.427 mestres (805 em cursos de MP e 622 em cursos de MA) contra apenas 215 doutores no ano de 2015. Esses dados demonstram um crescimento que não é acompanhado quando se observa a baixa quantidade de cursos de doutorado proporcionalmente aos de mestrado, o equivalente a $19 \%$, contrastando com outras áreas em que esse percentual é bem maior.

Entre as considerações sobre o MP na área de Ensino, encontramos os que relacionam aos PE aspectos positivos (MOREIRA; NARDI, 2009; DIÓRIO; RÔÇAS, 2014, LOCATELLI; ROSA, 2015). Para Moreira e Nardi (2009), é esperado para um PE o desenvolvimento de uma estratégia ou metodologia de ensino, entre outras possibilidades, podendo caracterizar tanto um processo quanto a geração de um produto a ser praticado em sala de aula. Em relação à pesquisa desenvolvida no $\mathrm{MP}$, esses autores entendem que o foco deve ser mais na aplicação do conhecimento com base em estudos do que na produção de uma mesma visão melhorada ano após ano.

Considerando o importante papel dos MP da área de Ensino, o estudo apresentado neste artigo se dedicou a análise dos PE desenvolvidos, por profissionais em formação continuada, a maioria professores de ciências, no Programa de Pós-Graduação Stricto Sensu em Ensino de Ciências (PROPEC) do Instituto Federal do Rio de Janeiro (IFRJ) localizado no município de Nilópolis, na região da Baixada Fluminense do Estado do Rio de Janeiro. Pretende-se, com isso, responder às seguintes perguntas: Como os PE do PROPEC estão distribuídos dentro das categorias propostas pelo documento de área de Ensino (BRASIL, 2013) nos últimos seis anos? O que as dissertações de MP do PROPEC indicam serem seus objetivos em relação ao ensino de ciências ao proporem os PE? Para responder tais perguntas, levamos em consideração a tipologia de PE constante do documento da área de Ensino (BRASIL, 2013): meios educativos; protótipos de ensino; propostas métodos de ensino; material textual; produtos interativos; atividades de extensão e o desenvolvimento de aplicativos. Além disso, foi realizada uma categorização à luz de indicadores gerais (público-alvo, modalidade de ensino e articulação ou não entre disciplinas), de forma a responder a primeira pergunta de pesquisa. Para a segunda, foi feito um aprofundamento por meio da leitura dos objetivos explicitados em cada um dos PE. Partindo do pressuposto que os PE resultam de uma reflexão feita pelos profissionais com base na prática pedagógica cotidiana, com foco na difusão dos produtos propostos e validados durante o desenvolvimento de dissertações de MP, buscamos, com os resultados, mostrar as contribuições desses materiais para o ensino de ciências.

\section{O PAPEL DO PRODUTO EDUCACIONAL}


do MP, incorpora-se uma dimensão aplicada à investigação realizada e que, de certa forma, possibilita suplantar a questão apontada por Arroyo $(2011$, p. 77) na qual os currículos e materiais didáticos não têm sido pensados a partir "de vivências da concretude social e política". Para esse autor, os currículos e todo o material que decorre de seu desenvolvimento não trazem a diversidade de contexto, região, raça, gênero etc., configurando saberes comuns que levam professores a "excluir seus saberes e os saberes sobre si mesmos porque não são dignos de entrarem no nobre núcleo comum" (ARROYO, 2011, p.78).

Em alguma medida, a aproximação da prática pedagógica na expressão do PE pode contribuir com uma discussão relevante para os estudos críticos no campo educacional que advogam um "currículo como produção das escolas, mediando pedagogicamente o social e o político" (LOPES, 2007, p. 206). Além disso, o lugar de destaque alcançado pelos livros didáticos como "versão didatizada do conhecimento para fins escolares e/ou com propósitos de formação de valores" deixa pouco espaço para a criação de saberes autorais dos profissionais da educação, já que, mesmo com toda qualidade dos livros didáticos, é importante questionar as propostas curriculares veiculadas neles, segundo Lopes (2007, p. 208). Os livros didáticos, assim como outros materiais, têm sido apresentados como propostas curriculares adaptáveis a qualquer cotidiano, o que é sabido não corresponder às diversas realidades dos professores e alunos. Debater o papel estabilizador e homogeneizador do livro didático, considerando-o como um meio de legitimação de um currículo que representa o status quo de uma elite nacional é essencial, pois estamos cientes de que ele é o recurso mais utilizado nas salas de aula e, por vezes, de forma acrítica. Assim, o PE desenvolvido em um MP pode ganhar contornos "subversivos" a essa prática hegemônica das políticas públicas e editoriais, pois o PE deve ser resultado de uma reflexão teórica-prática dos professores que buscam a academia. Ganhamos na modalidade profissional não somente um espaço de crítica ao livro didático, mas também de proposição de materiais que evitem operar na homogeneização dos saberes e vivências, e que recobrem identidades e experiências mais particulares e/ou locais das escolas.

Portanto, possibilitar que professores e alunos possam construir, de maneira conjunta, diretrizes, temas de currículo, formas de avaliação, atividades pedagógicas, entre outros, permite superar a dicotomia entre saber legítimo e não legítimo (ARROYO, 2011). No entanto, não é possível afirmar que ao elaborar seu PE o professor consiga incluir um saber para além daquele institucionalizado na tradição das políticas públicas e que, constantemente, desvalorizam o saber dos profissionais. Nesse sentido, Candau (2014, p. 36), referindo-se às práticas socioeducativas, entende que os processos educativos, por meio de suas dinâmicas, têm sido

padronizadores e uniformes, desvinculados dos contextos dos sujeitos que dele participam e baseados no modelo frontal de ensino-aprendizagem. Destaco dois aspectos incluídos nessa categoria de especial relevância para o desenvolvimento de práticas interculturais: a diferenciação pedagógica e a utilização das múltiplas linguagens e mídias no cotidiano escolar.

Ferreira (2014, p. 206) assevera a necessidade de desnaturalização de conteúdos e de práticas usuais das disciplinas, no sentido de se avançar para além das "relações que se estabelecem entre conhecimento e poder quanto às posições que temos ocupado" no que se refere aos currículos. Nessa linha, o incentivo à criação de PE autorais pode contribuir para pensar uma prática mobilizando 
competências diferenciadas das que têm se constituído como tradicionais para o ensino das diversas componentes curriculares. Quando nos referimos à autoria, compreendemos que essa engloba um conjunto de competências pedagógicas diferenciadas daquelas que usualmente temos como "tradicionais". A autoria voltada para a prática pedagógica

remete à intensificação das vivências dos acadêmicos com esses diferentes outros, em interações de toda ordem - para o foco desta discussão, mediadas pela escrita -, que criem possibilidades de alargamento de suas representações da realidade natural e social. (CERUTTI-RIZZATTI; DELLAGNELO, 2016, p. 65)

Além disso, Cerutti-Rizzatti e Dellagnelo (2016) entendem que a autoria permite um olhar exotrópico (BAHKTIN, 2003), ou seja, para além do que está colocado pela prática escolar, possibilitando ampliar os questionamentos e interrelações entre as dimensões da vida social. Portanto, permite ao professor desenvolver algo para além do conhecimento notacional, que visa apenas ao aprendizado das características da grafia da linguagem, seja ela qual for.

\section{METODOLOGIA}

A pesquisa configura-se como qualitativa e interpretativa. Uma primeira etapa do estudo voltou-se para o mapeamento dos PE desenvolvidos entre 2010 e 2015 por estudantes pós-graduados do PROPEC (RÔÇAS et al., 2011). Com isso, os setenta e cinco (75) PE foram classificados de acordo com a tipologia para a área de Ensino da CAPES (BRASIL, 2013), a saber: meios educativos (vídeos, simulações, vídeos, blogs, sites etc.); protótipos de ensino (atividades práticas e experimentais); propostas métodos de ensino (orientações práticas e experimentais, sequências didáticas, experiências e atividades práticas); material textual (manuais, textos de apoio, livros e outros); produtos interativos (jogos e similares); atividades de extensão (exposições científicas, cursos, palestras etc.); desenvolvimento de aplicativos. Outras modalidades tais como organização de eventos, programas de rádio e TV, peça teatral, relatórios, patentes e serviços técnicos não foram observados neste corpus de análise, uma vez que não estiveram presentes no recorte temporal analisado nesta investigação.

Para além da etapa de mapeamento das variantes entre os PE, realizamos uma categorização à luz de indicadores de forma a responder a primeira pergunta de pesquisa, começando pelas características descritivas tais como: público-alvo (professor, estudante, outros), escolaridade (ensino fundamental, ensino médio, etc.), modalidade de ensino (educação à distância, a juventude e educação de adultos, a educação não formal regular) e articulação ou não entre disciplinas (disciplinar, multidisciplinar, interdisciplinar, transdisciplinar, ausente). Na etapa seguinte demos ênfase aos recursos analíticos para responder, sobretudo, a segunda pergunta de pesquisa que procura entender que objetivos e resultados pedagógicos os mestres titulados visavam alcançar a partir dos PE desenvolvidos, na contribuição que esses têm para os processos autorais do ensino de ciências. Portanto, o presente estudo volta-se à investigação das possibilidades e expectativas dos PE tanto nos seus aspectos teórico-metodológicos quanto pela sua aplicabilidade em diferentes níveis e modalidades de ensino. 


\section{RESULTADOS}

Apresentamos, na Tabela 1, o mapeamento dos PE do MP do PROPEC quanto à tipologia sugerida pelo documento da CAPES.

Tabela 1 - Produtos educacionais do curso de MP do PROPEC do IFRJ.

\begin{tabular}{|cccccccc}
\hline Produto Educacional & 2010 & 2011 & 2012 & 2013 & 2014 & 2015 \\
\hline Mídia educacional & 3 & 6 & 1 & 3 & 2 & 3 \\
\hline Protótipo & - & - & - & 2 & - & - \\
\hline Proposta de ensino & - & - & - & 2 & - & - \\
\hline Material textual & 9 & 5 & 8 & 8 & 8 & 6 \\
\hline Produto interativo & 2 & 1 & 1 & - & - & - \\
\hline Atividade de extensão & - & - & - & - & 1 & - \\
\hline Desenvolvimento de aplicativo & 1 & 1 & 1 & - & 1 & - \\
\hline
\end{tabular}

(Fonte: Organizado pelos autores)

Identificamos que os 75 PE produzidos no PROPEC se enquadram em quase todas as modalidades sugeridas pelo documento da CAPES (BRASIL, 2013), com exceção de organização de eventos, programas de rádio e TV, relatórios, patentes e serviços técnicos, escolhas essas não realizadas pelos mestrandos no período de pesquisa recorte dessa investigação, e, portanto, não presente no corpus analisado. É importante destacar que esse conjunto não representa o quantitativo de alunos titulados no período de 2010 a 2015, fato justificado pela produção de mais de um PE como resultado no âmbito de uma mesma dissertação analisada no estudo. Embora tenhamos identificado 75 PE nas variantes da Tabela 1, neste artigo faremos um recorte de forma a aprofundar a modalidade textual (livros, paradidáticos, guias, manuais etc.), que totalizaram 44 desses, representando $57 \%$ do conjunto. Compreender o porquê dessa recorrência pode contribuir para a reflexão do que se alcança e porque se alcança por intermédio desse PE.

Outro aspecto que diz respeito à modalidade material textual é o de que, apesar de englobar uma mesma denominação, inclui formatos e aspectos semióticos diferenciados para os $\mathrm{PE}$, tais como textos de apoio, material didático, sequência didática, guia didático, entre outros. A escolha por essa modalidade também está ligada à familiaridade que os mestrandos possuem com recursos pedagógicos textuais, considerando a onipresença do livro didático nas salas de aulas.

Por outro lado, destacamos que esse aspecto se deve também ao baixo custo de produção de PE textuais, já que os MP não recebem qualquer tipo de fomento por parte da CAPES e/ou de outras agências de fomento, e muito menos de editoras, uma vez que os PE subvertem a lógica da exclusividade de um livro didático como fio condutor e estabilizador do currículo.

Os resultados mostram que para o formato material textual, a maior escolha dos mestrandos autores dos PE foi o texto de apoio. Isso parece corroborar com a predominância de textos escritos nas formas de expressão de materiais educativos, que têm reflexo em um ensino livresco. Essa tem sido uma preferência recorrente socialmente há algumas décadas, em comparação com outras possíveis 
formas semióticas. Historicamente, o material educativo impresso tornou-se o principal recurso pedagógico em sala de aula, assim como os livros, que se estabeleceram como os que mais contribuem para as práticas de educação científica, isto é, o que é ensinado sobre a ciência nas aulas de ciências (MOREIRA, 2013). No entanto, essa preferência pode caracterizar uma tendência em transição, uma vez que os resultados apontam um crescimento em relação às mídias educacionais como escolha para o desenvolvimento dos PE no programa de pós-graduação analisado.

Os PE como texto de apoio parecem corresponder a um formato análogo ao do livro didático, corroborando as questões trazidas anteriormente, de que essa variável é a mais utilizada/conhecida/disponibilizada no ambiente escolar. Porém a opção texto de apoio se distingue na medida em que, ao ser elaborado a partir do problema advindo de uma questão de pesquisa focada na prática pedagógica, sugere que os mestrandos autores do PE incorporem certa reação, e em grande parte de forma crítica, aos dispositivos pedagógicos hegemonicamente presentes na sala de aula (BERNSTEIN, 1986). Por exemplo, um PE na forma de texto de apoio que leve em consideração elementos de religiosidade e do conhecimento científico incorporando elementos da sociologia e filosofia para além dos científicos, entrelaçamento não muito comum nos livros didáticos. No entanto, temos clareza de que a crítica e/ou proposição de um PE não representa por si só uma mudança na prática de ensino, uma vez que esta exige igualmente macro mudanças de comportamento social radical na educação acompanhada de aprofundamento maior sobre as relações de poder mencionadas anteriormente no que incluímos como conhecimento legítimo e não legítimo. No exemplo mencionado, o texto de apoio pode se constituir legítimo para ser discutido em certas comunidades escolares, enquanto que em outras, por não identificarem claramente a intolerância religiosa, esse tipo de conhecimento pode não ser estimulado.

O estudo mostra que há lacunas em determinadas variáveis de PE previstas pelos documentos oficiais que norteiam a área de Ensino, tais como projetos de extensão e atividades de divulgação científica. Parece-nos que essas ausências podem estar relacionadas com as linhas de pesquisa desenvolvidas no programa analisado, mas também podem se referir à dificuldade de levantar recursos financeiros junto a órgãos de fomento. Ou seja, organizar um texto de apoio e alguns exemplares do mesmo se torna menos dispendioso do que desenvolver um projeto de extensão, por exemplo. Também foi observado que estudos envolvendo temas como educação ambiental, saúde e formação de professores são os mais comuns nas dissertações analisadas, reforçando a influência do papel desenvolvido pela adesão às linhas de pesquisa com demandas sociais e que, de certa forma, se constituem como referenciais teóricos menos comuns ao longo do processo educacional.

Uma vez selecionados, os PE foram lidos de forma a identificar os indicadores descritivos propostos para as quatro categorias pré-estabelecidas, a saber: público-alvo (professor, estudante, outros), escolaridade (ensino fundamental, ensino médio, etc.), modalidade de ensino (regular, educação à distância, educação de jovens e adultos, não educação formal) e articulação disciplinar (disciplinar, multidisciplinar, interdisciplinar, transdisciplinar, ausente). A última categoria (articulação disciplinar) foi a mais explorada analiticamente neste artigo, sobretudo pela leitura dos $\mathrm{PE}$, nos itens específicos dos objetivos a serem alcançados para o ensino de ciências. Em relação ao público-alvo, destaca-se na 
Figura 2 que a principal finalidade é o professor (59\%), indicando que os mestrandos que produziram os PE estão voltados para uma reflexão sobre suas próprias práticas e realidades, seguidas da proposição de atividades voltadas para os estudantes (18\%).

Figura 2 - Distribuição do público alvo dos produtos educacionais.

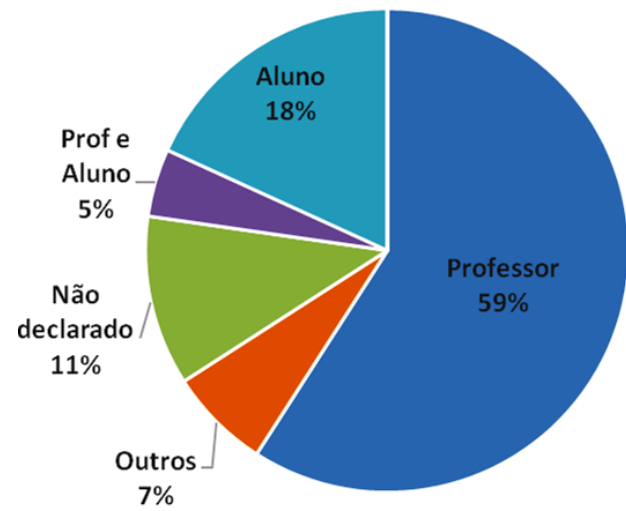

(Fonte: Organizado pelos autores)

Esse resultado está de acordo com Leodoro e Balkins (2010, p. 6), que defendem que o MP e o processo de elaboração de um PE é mais importante para professores do que todo o sistema educacional, porque durante a produção de um $\mathrm{PE}$, os professores

\footnotetext{
se dispõem, efetivamente, a se apropriarem de suas experiências de ensino e confrontá-las com referências teóricas em educação. Ou seja, se desejamos que os professores adotem uma prática de problematização junto aos seus alunos, ele próprio deverá vivenciar o ato de problematizar a sua prática pedagógica, ser protagonista dela.
}

O aspecto da apropriação de suas experiências, ressaltado por esses autores, figura como fundamental para a elaboração do que apontamos no referencial teórico da diferença entre um produto tradicional e outro autoral.

A Figura 3 a seguir indica o nível de escolaridade mais investigado, estabelecendo no ensino médio (43\%) um foco de maior preocupação, seguido do ensino fundamental (23\%). Essa preferência foi observada tanto por Von Dentz e Trucollo (2010) como por Teixeira (2012) ao analisarem as pesquisas sobre o ensino de ciências da natureza e a produção acadêmica do ensino de biologia no Brasil, respectivamente.

De acordo com Schwartzman (2010, p. 1), "está no ensino médio o gargalo mais crucial da educação no Brasil", citando como problemas para a evasão e desinteresse dos alunos, a carência de professores, em particular das disciplinas de química e física, a baixa cobertura na faixa etária, a restrição da dimensão do ensino técnico, o excesso de conteúdos, o currículo fragmentado, um repertório com pouca experimentação, entre outros. Por esse motivo, acredita-se que o desenvolvimento de PE por esses mestrandos esteja voltado, majoritariamente, ao ensino médio, com o intuito de despertar uma melhor prática acadêmica. 
Figura 3 - Produtos educacionais em relação ao nível de escolaridade.

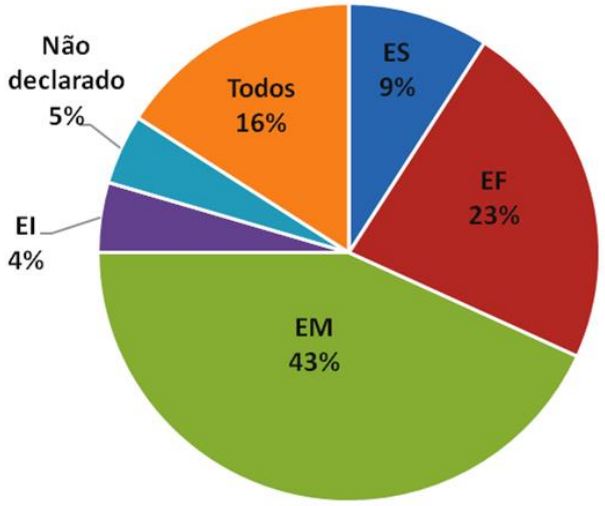

(Fonte: Organizado pelos autores)

No que diz respeito às modalidades de ensino, encontramos uma maior preocupação com o ensino formal, o que era de se esperar uma vez que os professores reconhecem esse como o seu nicho de atuação e liga-se ao propósito de conferir à ação profissional maior reflexão e contribuição. A segunda modalidade de ensino mais frequente foi a Educação de Jovens e Adultos (EJA), conforme apresentado na Figura 4, o que pode estar associado ao pouco material didático disponível para essa modalidade (FAVERO; BRENNER, 2006).

Figura 4 - Produtos educacionais em relação à modalidade de ensino.

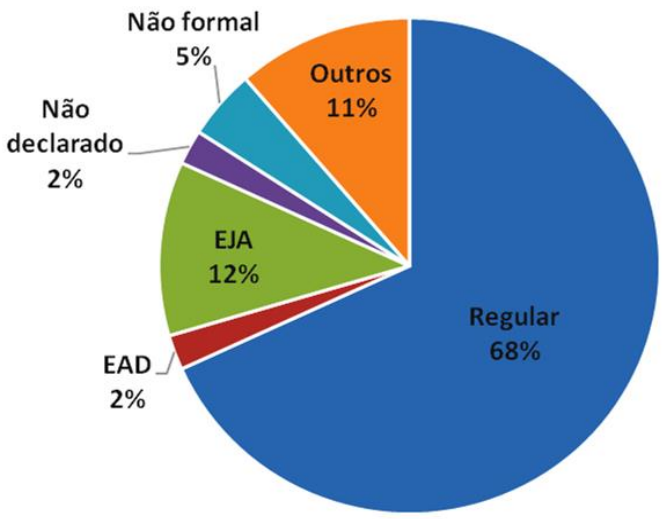

(Fonte: Organizado pelos autores)

No quesito das categorias descritivas, relacionado à possibilidade de articulação entre os conhecimentos envolvidos na produção dos $\mathrm{PE}$, alguns deles preocupam-se especificamente com uma disciplina (34\%), tais como os que focaram em temas específicos como relatividade, partículas elementares, evolução das espécies etc., repetindo o padrão encontrado em outros estudos (MEGID NETO, 2007). No entanto, o foco dos PE analisados, de uma maneira geral, voltou-se para aspectos multi, inter e transdisciplinar (64\%), conforme mostrado na Figura 5. 
Figura 5 - Produtos educacionais em relação à articulação entre disciplinas.

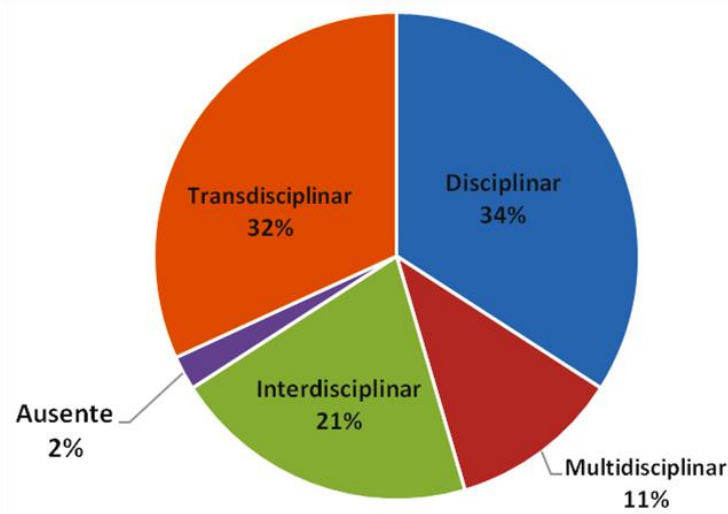

(Fonte: Organizado pelos autores)

Embora com certa cautela, consideramos o resultado interessante pelo quantitativo de autores dos PE que explicitaram ter considerado referenciais da interdisciplinaridade para o desenvolvimento do seu produto. De certa forma, essa parece ser uma preocupação teórica presente nas orientações do curso de pósgraduação analisado, por compreender um programa de Ensino de Ciências, da grande área multidisciplinar na CAPES. Nesse sentido, referenciais tais como os da sociologia, educação ambiental, CTS, análise do discurso, entre outros, possibilitam articular várias facetas do ensino de ciências, também observado em Delizoicov (2007) e Von Dentz e Trucollo (2010).

Ressaltamos aqui a cautela acima, pois sabemos que, tanto na formação de professores quanto no cotidiano da sala de aula da escola básica, a interdisciplinaridade surge de forma escassa e aligeirada, perpetuando a cisão e a hierarquização de saberes entre as ciências sociais e humanas e as ciências da natureza. Apesar de esse desafio estar posto para a escola nas diretrizes e parâmetros curriculares desde os anos 1990, ainda não foi incorporado de forma efetiva na formação dos profissionais que atuam na educação básica.

Para entender melhor essa questão, consideraram-se os objetivos a serem alcançados para o ensino de ciências no desenvolvimento dos PE de acordo com o declarado pelos mestrandos. Dentre os 44 PE como materiais textuais, apenas cinco (5) não especificaram os objetivos. Para além da descrição dos resultados alcançados, procuramos aprofundar os aspectos apontados nos objetivos dos PE, de forma a entender melhor, por exemplo, o que se espera do professor, uma vez que a maioria deles tinha esse público como destinatário.

Logo, quando nos voltamos aos objetivos dos PE foi possível identificar que muitas são as ações que estão nas intenções dos produtos desenvolvidos pelos mestrandos profissionais. Dentre as esperadas em relação aos professores, estão as seguintes: auxiliar, embasar, proporcionar, facilitar etc., apresentadas e exemplificadas no Quadro 1 a seguir.

Quadro 1 - Categorias de produtos educacionais voltados ao professor.

\begin{tabular}{|c|c|c|}
\hline CATEGORIA & AÇÕES & EXEMPLOS \\
\hline \multirow{2}{*}{ Colaborativa } & $\begin{array}{c}\text { auxiliar, ajudar, } \\
\text { contribuir, } \\
\text { colaborar, facilitar, }\end{array}$ & $\begin{array}{c}\text { "sugestões de atividades lúdicas que poderão } \\
\text { auxiliar o educador em suas práticas } \\
\text { pedagógicas" (PE30) }\end{array}$ \\
\hline
\end{tabular}




\begin{tabular}{|c|c|c|}
\hline & $\begin{array}{l}\text { lançar mão, } \\
\text { proporcionar }\end{array}$ & $\begin{array}{l}\text { "que os professores de Química podem } \\
\text { lançar mão para dinamizar as aulas" (PE18) } \\
\text { “objetivo desse material é proporcionar aos } \\
\text { professores um instrumento para facilitar a } \\
\text { exploração dos recursos educativos" (PE17) }\end{array}$ \\
\hline Construtivista & embasar, incentivar & $\begin{array}{l}\text { "foram elaborados a partir da necessidade de } \\
\text { dar um maior embasamento ao professor e } \\
\text { de referenciais teóricos apropriados" (PE2) }\end{array}$ \\
\hline
\end{tabular}

(Fonte: Organizado pelos autores)

Podemos perceber que há pelo menos duas formas de compreender o professor. A primeira entende que o professor é aquele que precisa de ajuda, facilitação e, portanto, a forma de traspor as dificuldades, que se dá pelo oferecimento de uma proposta ou sugestão. Nessa perspectiva, o professor é visto como alguém que, além de precisar de ajuda, precisa de alguém que pense por ele. Por outro lado, há os que entendem que o PE pode embasar formas diferenciadas de se ensinar, o que não garante necessariamente uma facilitação ou ajuda. Um segundo grupo mencionado pelos mestrandos para os quais os PE destinaram-se foram os alunos. Da mesma forma, identificamos diferentes ações, embora menos diversificadas daquelas direcionadas aos professores, tais como "proporcionar aos alunos" (PE15) e "capacitar o aluno a desenvolver uma visão integrada" (PE34). Apenas um exemplo trouxe o aluno como sujeito do aprendizado ao promover sua participação integral que pratica a ação (PE27).

Poucos foram os PE que se referiram ao nível escolar, evidenciando que esse não é um aspecto importante quando se pensa o que alcançar quando se elabora um PE. Trata-se de um fato inusitado, uma vez que há uma preocupação com o que pode ser ensinado a cada nível escolar, sendo importante definir o público ao qual se destina o PE para reconhecer qual melhor abordagem, linguagem e estética.

No aspecto modalidade de ensino, foi possível identificar que o ensino-formal não foi visto como uma maneira de aprender conteúdos, muito presente nos objetivos de planos de aula. As ações sugeridas para o ensino formal envolveram questionamento, promoção da leitura, divulgação de importantes temas, reflexão e apreensão acerca do ensino proposto, denotando mais preocupação com procedimentos do que com conteúdos. No entanto, alguns apresentaram objetivos mais específicos tal como, "apresentar conceitos e informações, de forma sintética" (PE03). Outro aspecto da modalidade de ensino diz respeito à EJA, representada duas vezes nos objetivos dos mestrandos, uma delas mais voltada ao ensino interdisciplinar e outra à ludicidade.

No quesito articulação de conhecimentos, a interdisciplinaridade foi muito citada nos objetivos dos PE. No entanto, sabemos que ela ainda é idealizada pelos mestrandos, e, muitas vezes, atividades planejadas de forma interdisciplinar não são tão fáceis de serem postas em prática, permanecendo no plano retórico do discurso. $O$ resultado nesse item diverge um pouco do que encontramos na descrição dos $\mathrm{PE}$, em que o termo transdisciplinar foi mais mencionado pelos mestrandos. Entendemos também que as ações interdisciplinares nem sempre têm o mesmo significado, além de ser apresentadas nos PE de forma diferenciada (Quadro 2). 
Quadro 2 - Expressões utilizadas para expressar a interdisciplinaridade.

\begin{tabular}{|c|c|}
\hline Categoria & Expressões \\
\hline 1 & Forma Interdisciplinar \\
\hline 2 & Atividades interdisciplinares \\
\hline 3 & Proposta interdisciplinar \\
\hline 4 & Trabalho interdisciplinar \\
\hline 5 & Abordagem interdisciplinar \\
\hline 6 & Campo interdisciplinar \\
\hline
\end{tabular}

(Fonte: Organizado pelos autores)

Algumas expressões têm significado mais voltado a uma atividade ou proposta de ensino, enquanto outras se voltam mais ao aspecto epistemológico do ensinar (abordagem e campo). Esses resultados apontam para uma preocupação que se contrapõe à fragmentação do conhecimento encontrada nas escolas, fato relevante na possibilidade que o ensino de ciências propõe articular questões históricas, sociais, cientificas entre outras (EL-HANI, 2007).

Esses resultados nos permitem inferir que os PE analisados constituem materiais com questões pautadas em diversas dimensões - políticas, pedagógicas e epistemológicas, entre outras - levando em consideração tanto os elementos do saber legítimo, mas também apontando questões para além dele. Nesse sentido, os $\mathrm{PE}$ autorados por mestrandos da modalidade profissional possibilitam maneiras de desnaturalizar o ensino de ciências.

\section{CONSIDERAÇÕES FINAIS}

Percebemos que os PE desenvolvidos entre 2010 e 2015 no curso de MP do PROPEC/IFRJ se encontram distribuídos dentro da maioria das categorias propostas para a tipologia de produtos pelo documento de área de Ensino, e que as dissertações indicam a interdisciplinaridade como forte objetivo a ser alcançado em relação ao ensino de ciências. Entendemos que os mestres profissionais têm estabelecido um compromisso com as questões mais amplas da educação, e, em particular neste estudo, do ensino de ciências, sobretudo às condições da docência, nas atividades formais diárias de ensino, com um interesse ainda focalizado no ensino médio e direcionado a ações inter, multi e transdisciplinares.

Não foram encontrados, no período analisado, PE voltados para projetos de extensão e atividades de divulgação científica, o que pode estar relacionado com as linhas de pesquisa desenvolvidas no programa de pós-graduação e na progressiva redução de fomento, sobretudo para a modalidade profissional que já carece tanto ao não receber auxílios de agências de fomento tais como bolsas de estudo, PROAP, entre outros.

Apontamos ainda como incipiente a escolha dos mestrandos profissionais em desenvolver PE voltados ao ensino fundamental, em especial aos anos iniciais. A pesquisa também mostrou que há uma precariedade nos investimentos em PE relacionados à divulgação científica, caso esse que evidencia para uma ação que venha suprir tal lacuna. Por fim, a análise aponta que os PE fortalecem elementos seu ambiente de trabalho. No entanto, ainda se faz necessário aprofundar os 
estudos sobre os PE de forma a permitir reflexão sobre os elementos da prática educativa e suas possibilidades de transformação tanto do ensino como da sociedade.

Os PE têm a possibilidade de responder de forma mais rápida às exigências e demandas feitas à educação básica, podendo fazer isso de forma crítica e reflexiva. Se proposto de forma clara, respaldado e bem fundamentado, o PE pode se configurar como um recurso que rompa com a hegemonia das editoras e do livro didático, além de resistir, por exemplo, às proposições da Base Nacional Comum Curricular (BNCC).

Muito mais do que inovador, um PE precise ser subversivo, algo próximo ao sentido dado por Leodoro e Balkins (2010) ao entenderem o PE como transacional, aquele que, mesmo tendo sido elaborado para contexto específico, pode e deve ser adaptado e reinterpretado. Deve ser proposto para ter um caráter interdisciplinar, estabelecendo uma ponte entre as ciências humanas, sociais e da natureza, licenciado na perspectiva de criative commons, gratuito, aberto para novas inclusões. Um PE desenvolvido no âmbito dos programas de pós-graduação de Ensino na modalidade profissional deve pressupor construção coletiva e dinâmica, sendo esse nosso novo desafio, sobretudo com os doutorados profissionais que se aproximam de iniciar em 2019.

\section{AGRADECIMENTOS}

Agradecemos ao IFRJ e a FAPERJ pelo fomento e bolsas concedidos no período em que esse estudo foi realizado. Fazemos um agradecimento especial aos pareceristas da revista, os quais, após leitura atenta e cuidadosa, estabeleceram diálogos propositivos, gentis e instigadores, nos possibilitando melhorar as reflexões propostas neste estudo, e, principalmente, instigou-nos a pensar mais e além para pesquisas futuras. 


\title{
Educational products in a professional master's degree course
}

\begin{abstract}
How are the educational products of a course distributed within the categories proposed by the science education area document in the last six years? What do Professional Master's dissertations indicate their goals in proposing educational products? Based on the research questions described, the article refers to educational products produced in a Professional Master's in science education, seeking to understand how such productions contribute and / or reinforce approaches to science education. It is a qualitative research where we mapped the educational products of the graduate program of professional masters of Federal Institute of Rio de Janeiro, seeking the theoretical and methodological aspects regarding the science education proposals. The results highlight preferences - educational media and text supplies - and showed a lack of investments in educational products related to science divulgation, and academic extension. Pointed to enhance studies on educational products to reflect on educational practice elements to improve science education in these courses.
\end{abstract}

KEYWORDS: Professional master degree. Educational products. Science education. 


\section{REFERÊNCIAS}

ARROYO, M. G. Currículo, território em disputa. Petrópolis: Vozes, 2011.

BAKHTIN, M. Estética da Criação Verbal. Martins Fontes, São Paulo, 2003.

BALATSOUKAS, P; MORRIS, A.; O'BRIEN, E. A. Learning objects update: review and critical approach to content aggregation. Educational Technology \& Society, v. 11, n. 2, 2008. Disponível em: <http://ifets.info/journals/11_2/11.pdf>. Acesso em: 16 mar. 2017.

BERNSTEIN, B. On pedagogic discourse. In: RICHARDSON, J. G. (Ed.). Handbook of theory and research for sociology of education. New York: Greenwood Press, 1986.

BRASIL. Ministério da Educação. Coordenação de Aperfeiçoamento de Pessoal de Nível Superior. Portaria Normativa n. 17. 2009. Disponível em:

<https://www.capes.gov.br/images/stories/download/legislacao/PortariaNormat iva_17MP.pdf>. Acesso em: 23 mar. 2016.

Ministério da Educação. Coordenação de Aperfeiçoamento de Pessoal de Nível Superior. Documento de área 2013 (Ensino). 2013. Disponível em: <https://www.capes.gov.br/images/stories/download/avaliacaotrienal/Docs_de_ area/Ensino_doc_area_e_comiss\%C3\%A3o_block.pdf>. Acesso em: 16 mar. 2017.

CANDAU, V. M. Educação intercultural: entre afirmações e desafios. In: MOREIRA, A. F.; CANDAU, V.M. (Org.) Currículos, disciplinas escolares e culturas. Petrópolis: Vozes, 2014.

CAVALCANTE, D. A. Os produtos educacionais de química desenvolvidos por mestrados profissionais em ensino de ciências no Brasil. Dissertação (mestrado) - Programa de Pós-graduação em Ensino de Ciências e Matemática, Universidade Federal do Ceará, Fortaleza, 2015. Disponível em:

<http://www.repositorio.ufc.br/handle/riufc/11054>. Acesso em: 16 mar. 2017.

CERUTTI-RIZZATTI, M. E; DELLAGNELO. A. C. K. Desafios à educação para a autoria na esfera acadêmica. Ilha do Desterro, v. 69, n. 3, p. 63-76, 2016.

CGEE. Centro de Gestão e Estudos Estratégicos. Mestres 2012: estudo da demografia da base técnico-científica brasileira. Brasília: CGEE, 2012. 
<https://www.cgee.org.br/documents/10195/734063/MeD2015.pdf/d46864747a32-4bc9-91ae-eb5421e0a981>. Acesso em: 16 mar. 2017.

CRUZ, C. Competências e habilidades: da proposta à prática. São Paulo: Edições Loyola, 2001.

DELIZOICOV, D. Pesquisa em ensino de ciências como ciências humanas aplicadas. In: NARDI, R. (Org.). A pesquisa em ensino de ciências no Brasil: alguns recortes. São Paulo: Escrituras, 2007.

DIÓRIO, A. P. I. RÔÇAS, G. Pensando o Ensino de Ciências e Biologia a partir da construção de produtos educacionais: um relato de experiência. Revista de Ensino de Biologia da Associação Brasileira de Ensino de Biologia (SBEnBio), v. 7, p. 504-516, 2014. Disponível em: <http://www.sbenbio.org.br/wordpress/wpcontent/uploads/2014/11/R0723-1.pdf>. Acesso em: 16 mar. 2017.

EL-HANI, C. N. Notas sobre o ensino de história e filosofia da biologia na educação superior. In: NARDI, R. (Org.). A pesquisa em ensino de ciências no Brasil: alguns recortes. São Paulo: Escrituras, 2007.

FAVERO, O.; BRENNER, A. K. Programa de Educação de Jovens e Adultos (PEJA). In: REUNIÃO DA ANPED, 28., 2006. Atas... Caxambu: ANPED, 2006. Disponível em: <http://29reuniao.anped.org.br/trabalhos/trabalho/GT18-2088--Int.pdf>. Acesso em: 16 mar. 2017.

FERNANDES, A. Mestrado profissional - algumas reflexões. Oculum Ensaios Revista de Arquitetura e Urbanismo, n. 4, p. 107-110, 2005. Disponível em: $<$ http://periodicos.puccampinas.edu.br/seer/index.php/oculum/article/view/790>. Acesso em: 16 mar. 2017.

FERREIRA, M. S. Currículo e cultura: diálogos com disciplinas escolares Ciências e Biologia. In: MOREIRA, A. F.; CANDAU, V. M. (Org.) Currículos, disciplinas escolares e culturas. Petrópolis: Vozes, 2014.

KRESS, G.; VAN LEEUWEN, T. Reading images: the grammar of visual design. London; New York: Routledge, 2006.

LEODORO, M. P.; BALKINS, M. A. A. S. Problematizar e participar: elaboração de produto educacional no Mestrado Profissional em Ensino. In: SIMPÓSIO NACIONAL DE ENSINO DE CIÊNCIA E TECNOLOGIA, 2., 2010. Anais... Ponta Grossa: UTFPR, 2010. Disponível em: <http://www.sinect.com.br/anais2010/artigos/EF/84.pdfs. Acesso em: 16 mar. 2017. 
LOCATELLI, A.; ROSA, C. T. W. Produtos Educacionais: características da atuação docente retratada na I Mostra Gaúcha. Polyphonia, v. 26, n. 1, p.197-210, 2015. Disponível em: <http://www.revistas.ufg.br/sv/article/view/37990>. Acesso em: 16 mar. 2017.

LOPES, A. C. Currículo e epistemologia. ljuí: Unijuí, 2007.

MEGID-NETO, J. Três décadas de pesquisas em educação em ciências: tend6encias de teses e dissertações (1972-2003). In: NARDI, R. (Org.). A pesquisa em ensino de ciências no Brasil: alguns recortes. São Paulo: Escrituras, 2007.

MOREIRA, M. A. O mestrado (profissional) em ensino. Revista Brasileira de PósGraduação, ano 1, n. 1, p. 131-142, 2004. Disponível em: <http://ojs.rbpg.capes.gov.br/index.php/rbpg/article/view/26>. Acesso em: 16 mar. 2017.

MOREIRA, M. A.; NARDI, R. O mestrado profissional na área de Ensino de Ciências e Matemática: alguns esclarecimentos. Revista Brasileira de Ensino, Ciência e Tecnologia, v. 2, n. 3, 2009. Disponível em: <https://revistas.utfpr.edu.br/rbect/article/view/549/398>. Acesso em: 16 mar. 2017.

MOREIRA, M. C. A. A recontextualização do discurso da pesquisa em educação em ciências em uma coleção didática de ciências. 2013. 168p. Tese (doutorado) - Programa de Pós-graduação em Educação em Ciências e Saúde, Universidade Federal do Rio de Janeiro, Rio de Janeiro, 2013.

POSSOLI, G. E; CURY, P. Q. Reflexões sobre a elaboração de materiais didáticos para educação a distância no Brasil. In: CONGRESSO NACIONAL DE EDUCAÇÃO, 9., 2009. Atas... Curitiba: PUCPR, 2010. Disponível em: <http://www.pucpr.br/eventos/educere/educere2009/anais/pdf/2558_1546.pdf>. Acesso em: 16 mar. 2017.

RANGEL, E. O. Avaliar para melhor usar - avaliação e seleção de materiais e livros didáticos. In: BRASIL. MEC. Materiais didáticos: escolha e uso. 2005. Disponível em: <https://marcosfabionuva.files.wordpress.com/2015/02/mec-materiaisdidaticos-escolha-e-uso.pdf>. Acesso em: 16 mar. 2017.

RÔÇAS, G., SIQUEIRA-BATISTA, R.; BOMFIM, A. M.; ANJOS, M. B. O mestrado profissional em ensino de ciências do Instituto Federal de Educação, Ciência e Tecnologia do Rio de Janeiro: o desafio do ensino de pós-graduação na região da baixada fluminense do Rio de Janeiro. Ensino, Saúde e Ambiente, v. 4, n. 2, 2011. 
$<$ http://www.ensinosaudeambiente.uff.br/index.php/ensinosaudeambiente/artic le/view/91/90>. Acesso em: 16 mar. 2017.

SCARANO, F. R.; OLIVEIRA, P. E. A. M. Sobre a importância da criação de mestrados profissionais na área de ecologia meio ambiente. Revista Brasileira de Pós-Graduação, v. 2, n. 4, p. 90-96, 2005. Disponível em: <http://ojs.rbpg.capes.gov.br/index.php/rbpg/article/view/81>. Acesso em: 16 mar. 2017.

SCHWARTZMAN, S. O ensino médio no Brasil é formal, acadêmico, voltado para o vestibular. Não atende jovens com outros interesses. 2010. Disponível em: $<$ https://www.revistaensinosuperior.gr.unicamp.br/entrevistas/simonschwartzman-o-ensino-medio-no-brasil-e-formal-academico-voltado-para-ovestibular-nao-atende-jovens-com-outros-interesses>. Acesso em: 16 mar. 2017.

SPINK, P. A. Formação Acadêmica e a Ciência: ampliando o debate sobre o mestrado profissional debate sobre o mestrado profissional. RAC, v. 1, n. 3, p. 163-169. 1997. Disponível em:

<http://www.scielo.br/pdf/rac/v1n3/v1n3a09.pdf>. Acesso em: 16 mar. 2017.

TEIXEIRA, P. M. M. (Org). 35 anos da produção acadêmica em ensino de biologia no Brasil: catálogo analítico de dissertações e teses (1972-2006). Vitória da Conquista: Edições UESB, 2012. Disponível em:

$<$ http://www.uesb.br/ppgecfp/livros/catalogo-teses.pdf>. Acesso em: 16 mar. 2017.

VON DENTZ, V.; TRUCOLLO, F. Mapeamento de pesquisas (teses e dissertações) sobre o Ensino de Ciências da Natureza (Física, Química e Biologia) nos níveis fundamental e médio. Revista Técnico-Científica do IFSC, v. 2, n. 1, p. 90-99, 2010. Disponível: <http://periodicos.ifsc.edu.br/index.php/rtc/article/view/973>. Acesso em: 16 mar. 2017. 
Recebido: 2017-03-16

Aprovado: 2018-08-15

DOI: $10.3895 /$ rbect.v11n3.5697

Como citar: MOREIRA, M. C. A.; RÔÇAS, G.; PEREIRA, M. V.; ANJOS, M. B. Produtos educacionais de um curso de mestrado profissional em ensino de ciências. Revista Brasileira de Ensino de Ciência e Tecnologia, v. 11, n. 3, 2018. Disponível em: <https://periodicos.utfpr.edu.br/rbect/article/view/5697>. Acesso em: xxx. Correspondência: Maylta Brandão dos Anjos - maylta.anjos@ifrj.edu.br Direito autoral: Este artigo está licenciado sob os termos da Licença Creative Commons-Atribuição 4.0 Internacional. 